\title{
PREPARATION AND CHARACTERIZATION OF MASTER ALLOYS SUITABLE FOR THE PRODUCTION OF INTERMETALLIC COMPOUNDS BASED ON GAMMA-TIAI
}

\author{
Tomáš ČEGAN, Daniel PETLÁK, Jan JUŘICA \\ VSB - Technical University of Ostrava, Ostrava, Czech Republic, EU \\ tomas.cegan@vsb.cz
}

https://doi.org/10.37904/metal.2019.956

\begin{abstract}
$\mathrm{y}$-TiAl based alloys are very perspective materials thanks to their outstanding properties, such as high specific strength, low density, high modulus of elasticity, good oxidation resistance and resistance to creep. At present, the greatest attention is paid to TiAl alloys which contain relatively high content of refractory metals such as $\mathrm{Nb}, \mathrm{Ta}, \mathrm{Mo}$ and $\mathrm{W}$. The main objective of this paper is, how to transform the refractory $\mathrm{W}, \mathrm{Ta}$ or $\mathrm{Nb}$ into the form of master alloys, suitable for preparation of heavy alloyed $\mathrm{y}$-TiAl intermetallic alloys and characterize the homogeneity, microstructure and other properties (oxygen content, melting temperature) important for their further using.
\end{abstract}

Keywords: Intermetallics, refractory metals, microstructure, plasma melting

\section{INTRODUCTION}

Modern technology is increasingly confronted with temperature limitations. There is a never ending search for the materials capable of performing desired functions at both higher and lower temperatures. Refractory metals are a class of metals that are extraordinarily resistant to heat and wear. Their usage however does not include only single crystal or polycrystalline pure metals applications, but much more as alloying elements for various alloys. Highly alloyed steels, Ni-based superalloys, $\mathrm{Y}$-TiAl based alloys and others are characterized by high hardness and heat resistance and are currently largely exploited for highly thermally and mechanically stressed components [1-6]. Especially $\mathrm{Y}$-TiAl based alloys are considered as an important class of alloys providing a unique set of physical and mechanical properties that can lead to substantial payoffs in the automotive industry, power plant turbines and aircraft engines. Nowadays, the intermetallic $\mathrm{y}$-TiAl alloys of great engineering interest follow the chemical compositions in the range Ti-(45-48)Al-(1-10)M (at\%), with $\mathrm{M}$ being at least one element from $\mathrm{V}, \mathrm{Cr}, \mathrm{Mn}, \mathrm{Nb}, \mathrm{Ta}, \mathrm{W}$, and $\mathrm{Mo}$. Alloying by refractory metals can increase the liquidus temperature of $y$-TiAl alloys, improve high temperature strength, creep resistance and oxidation resistance [6-8]. However high melting point of refractory metals (over $2400{ }^{\circ} \mathrm{C}$ ) deteriorates the preparation of heavy alloyed $\mathrm{Y}$-TiAl based products by conventional casting with using of pure metals charge, because it is necessary to use high temperatures and thus generally a longer total time of melting. Longer melting time may cause increase of oxygen content, which usually negatively affects the mechanical properties of $\mathrm{y}$-TiAl based alloys [9]. Often may also become incomplete dissolution of the refractory metals in the products [8]. The use of suitable master alloys for the preparation of the refractory metals alloyed $\mathrm{y}$-TiAl based alloys is highly suitable because of reduction of temperature during melting and suppression of high melting phases in multinary alloy systems. The suitable master alloys should be characterized by the melting temperature of approx. $1600-1650{ }^{\circ} \mathrm{C}$, high purity and homogeneity and low content of interstitial elements, particularly of oxygen. The master alloys are should be characterized by the acceptable melting temperature and their chemical composition can also be considered as suitable for preparation of the final $\mathrm{Y}$-TiAl alloys from the viewpoint of easy preparation of charges with composition Ti-(45-48)Al-(1-10) Nb,Ta,W (at\%). The aim of the present work is to develop methods suitable for preparing of master alloys of the following composition and characterize the homogeneity, microstructure and another properties (oxygen content, melting temperature) important for their further using for preparation of heavy alloyed $\mathrm{y}$-TiAl alloys. 


\section{EXPERIMENT}

Commercially available metals (purity $99.9 \%$ ) were cut to the form of $10 \times 20 \times 40 \mathrm{~mm}$ Al plates, $1 \times 10 \mathrm{~mm}$ W wires, $2 \times 10 \mathrm{~mm} \mathrm{Nb}$, or Ta wires and have been used as input materials for melting. Applied method was plasma arc zone melting (PAM) with using horizontal water-cooled copper mould. The location of the charge was as follows: the wires of the refractory metals in the center and pieces of $\mathrm{Al}$ or $\mathrm{Ti}$ in the bottom and upper part of the crystallizer in the vertical direction. After evacuation and flush by $\operatorname{Ar}$ (purity $99.95 \%$ ), the plasma torch was started and melting were done with the rate of shift of the mould $0.5 \mathrm{~cm} / \mathrm{min}$ in an flowing $\mathrm{Ar}$ atmosphere $(27 \mathrm{l} / \mathrm{min})$ and with the maximum current density of $800 \mathrm{~A}$. After every two re-melting (second melting were always in the opposite direction than previous), the ingots were rotated by 180 degrees in vertical direction. The products were oval cross-section ingots with diameter about 18 and $8 \mathrm{~mm}$ and length $140-150$ $\mathrm{mm}$, which typical example can be seen in Figures 1,2. A list of all prepared alloys including the used method shows Table 1. The samples for metallographic observations were prepared with the standard metallographic method including the initial grinding on the sandpapers and polishing with an $\mathrm{Al}_{2} \mathrm{O}_{3}$ suspension. For the observation of the microstructure and the analysis of the chemical composition we used a scanning electron microscope QUANTA FEG 450 equipped with an EDAX APOLLO X probe. The oxygen amount was measured with the thermo-evolution method using an ELTRA ONH-2000 instrument. The DTA analysis was performed with the experimental equipment Setaram SetSys 1750 and the samples were analysed in corundum crucibles with an internal coating of $\mathrm{Y}_{2} \mathrm{O}_{3}$ at a heating rate of $10{ }^{\circ} \mathrm{C} / \mathrm{min}$ and in an atmosphere of argon with the purity of $6 \mathrm{~N}$.

Table 1 List of all prepared master alloys

\begin{tabular}{|c|c|c|c|}
\hline Alloy & Nominal composition (at\%) & Number of passes & Weight of charge $(\mathrm{g})$ \\
\hline Nb-Al-1 & 40Nb-60Al & 4 & 160 \\
\hline Nb-Al-2 & 40Nb-60Al & 2 & 160 \\
\hline Ta-Al & 20Ta-80Al & 6 & 180 \\
\hline W-Al-1 & 15W-85Al & 4 & 150 \\
\hline W-Al-2 & 15W-85Al & 6 & 150 \\
\hline
\end{tabular}

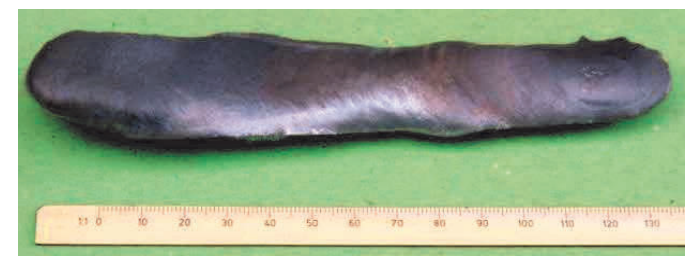

Figure 1 Ta-Al master alloy

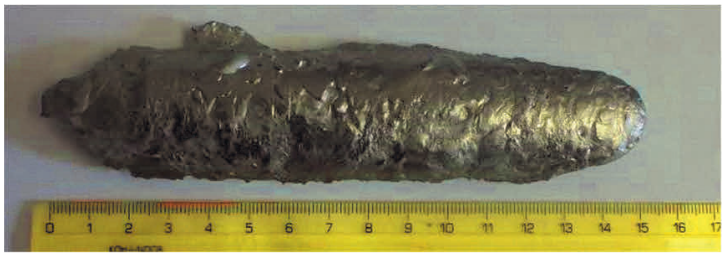

Figure 2 W-Al-1 master alloy

\section{RESULTS AND DISCUSSION}

During the all melting processes $\mathrm{Nb}$ and Ta wires completely dissolve in the Al melt, which was verified by the absence of insoluble residues of the wires inside the castings. Figure 3 exhibit an un-melted areas in the WAl-1 master alloy prepared by mentioned method. This area over $1 \mathrm{~mm}^{2}$ was identified as pure tungsten by EDS analysis (see Table in Figure 3), suggesting that this area failed to be melted due to high melting point of tungsten. Around the not melted tungsten areas can be observed a thin continuous layer of intermetallic phase based on tungsten and aluminium, small particles of intermetallic phases and further away from the not molten tungsten can be observed long needles-like particles of WAl 4 phase in $\mathrm{Al}$ matrix. In order to avoid the persistence of un-melted areas, the new experiment of plasma arc melting with same conditions only with sixfold passes was executed. Higher current density was not used because $800 \mathrm{~A}$ is the maximum current density 
for safety reasons. Figure 4 exhibit the microstructure after the melting and as can be seen in this figure the microstructure are almost the same and the not melted areas are observed as well. Mentioned method is therefore unsuitable for the preparation of master alloys W-Al due to existence of non-melted areas in the products, that could not be removed even multiple re-melting. For this reason, PAM ingots were re-melted in a vacuum induction furnace using a commercial $\mathrm{Al}_{2} \mathrm{O}_{3}$ crucible in $\mathrm{Ar}$ atmosphere with pressure about $20 \mathrm{kPa}$ and poured into the copper mould. Only a little bit of undissolved $W$ wire remained at the bottom of the melting crucible after this re-melting and casting and there were no $\mathrm{W}$ wires in the casting.

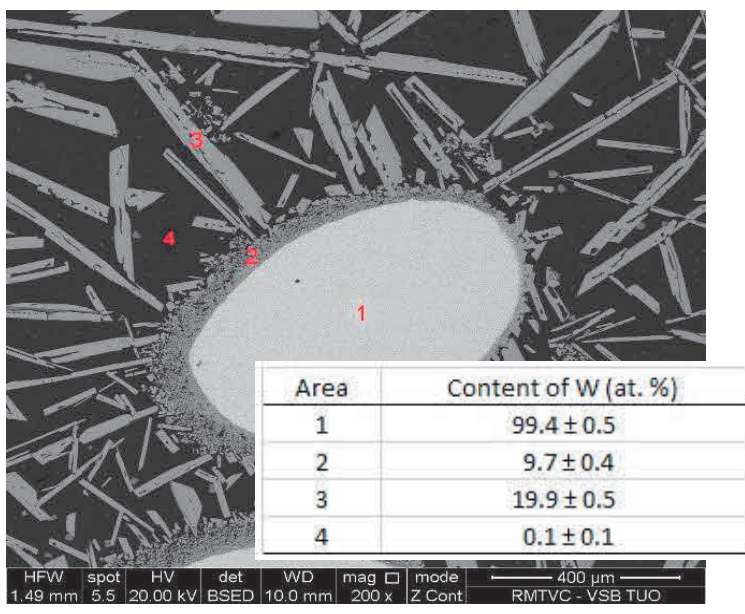

Figure 3 SEM-BSE image of the W-Al-PAM-1 alloy

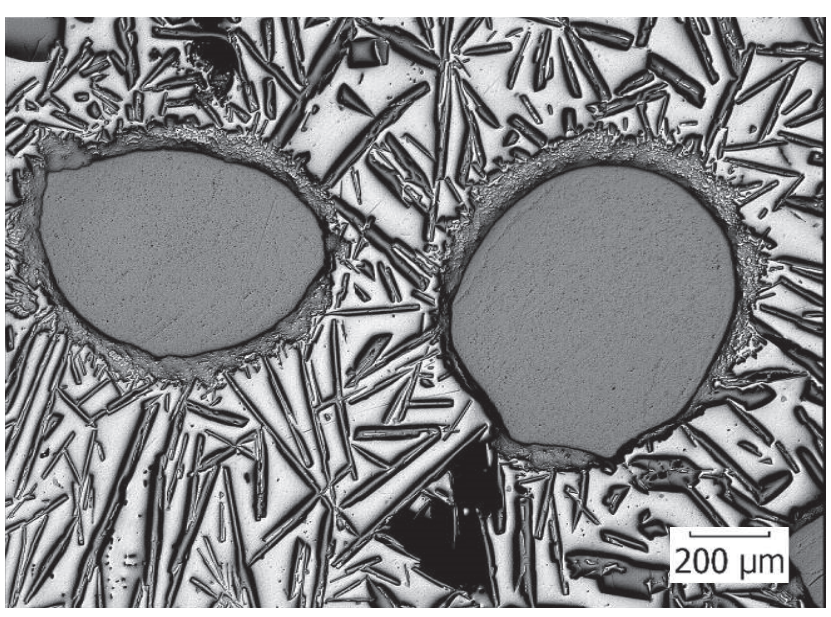

Figure 4 OM image of W-Al-PAM-2-alloy

In every melted sample at a temperature about $1400-1500{ }^{\circ} \mathrm{C}$ a small amount of smoke started to escape from melting crucible and condensing at the inner walls of the furnace and at glass windows. An EDS analysis of condensed powder revealed the composition based on pure aluminium which evaporated during melting, confirming the findings of other authors [10,11]. Aluminium loss after PAM is related to the high vapour pressure of aluminium, especially with the higher achieved temperatures during PAM, which allows reach temperatures up to several thousand ${ }^{\circ} \mathrm{C}$ (the evaporation temperature of $\mathrm{Al}$ is $2519^{\circ} \mathrm{C}$ ). Aluminium evaporation during PAM also indicate results of EDS analysis (see Table 2), which exhibit more pronounced decrease in the aluminium content in ingot Nb-Al-1 (4 passes) than in ingot Nb-Al-2 (2 passes) and for W-Al samples a similar development was observed.

Table 2 Chemical composition of prepared master alloys

\begin{tabular}{|c|c|c|c|c|c|c|}
\hline \multirow{2}{*}{ Alloy } & \multirow{2}{*}{$\begin{array}{l}\text { Nominal composition } \\
\text { (at } \%)\end{array}$} & \multicolumn{4}{|c|}{$\begin{array}{l}\text { Measured chemical composition of the master alloy by EDS } \\
\text { (at. \%) }\end{array}$} & \multirow{2}{*}{$\begin{array}{l}\text { Oxygen content } \\
\text { measured by the } \\
\text { thermo-evolution } \\
\text { method (wt ppm) }\end{array}$} \\
\hline & & $\mathrm{Al}$ & $\mathrm{Nb}$ & $\mathrm{Ta}$ & W & \\
\hline $\mathrm{Nb}-\mathrm{Al}-1$ & $40 \mathrm{Nb}-60 \mathrm{Al}$ & Bal. & $43.6 \pm 0.5$ & - & - & $60 \pm 14$ \\
\hline $\mathrm{Nb}-\mathrm{Al}-2$ & $40 \mathrm{Nb}-60 \mathrm{Al}$ & Bal. & $41.9 \pm 0.4$ & - & - & $54 \pm 24$ \\
\hline Ta-Al & $20 \mathrm{Ta}-80 \mathrm{Al}$ & Bal. & - & $23.2 \pm 1.3$ & - & $123 \pm 20$ \\
\hline W-Al-1 & $15 \mathrm{~W}-85 \mathrm{Al}$ & Bal. & - & - & $15.9 \pm 3.1$ & $213 \pm 34$ \\
\hline W-Al-2 & $15 \mathrm{~W}-85 \mathrm{Al}$ & Bal. & - & - & $16.5 \pm 2.6$ & $242 \pm 41$ \\
\hline
\end{tabular}

Micro-structure of the prepared $\mathbf{~} b$-Al master alloys is shown in Figures $\mathbf{5}$ and $\mathbf{6}$. As can be seen on these figures, the microstructure is nearly dendritic with coarser white dendrites and eutectics between the dendrites. Dendrites is formed by $\mathrm{Nb}_{2} \mathrm{Al}$ phase (tP30) referred as o phase in the literature, which are in micrographs 
presented by light colour, and by $\mathrm{NbAl}_{3}$ phase (tl8), which is presented in the enclose micrographs by dark colour. Average contents of elements in individual phases calculated from the measured chemical composition according to EDS were in the all ingots areas almost the same and niobium contents were about 56 - 57, 24 26 and $39-41$ at\% for coarse $\mathrm{Nb}_{2} \mathrm{Al}$ phases, for $\mathrm{NbAl}_{3}$ phases and eutectic, respectively. Occurrence of the phases $\mathrm{Nb}_{2} \mathrm{Al}$ and $\mathrm{NbAl}_{3}$ was confirmed also by the $\mathrm{X}$-ray diffraction pattern (not presented in this article). Microstructures therefore exhibit the features of hypoeutectic alloy, for which is primary solidification phase $\mathrm{Nb}_{2} \mathrm{Al}$.

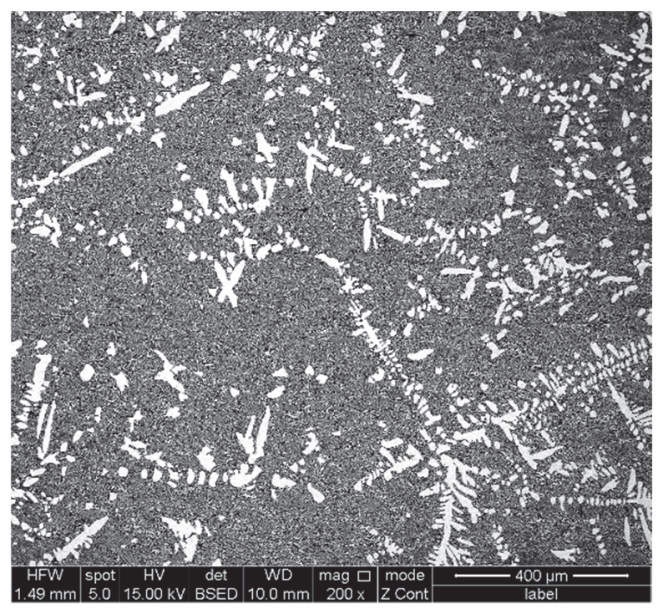

Figure 5 The microstructure of $\mathrm{Nb}-\mathrm{Al}-1$ master alloy (BSE)

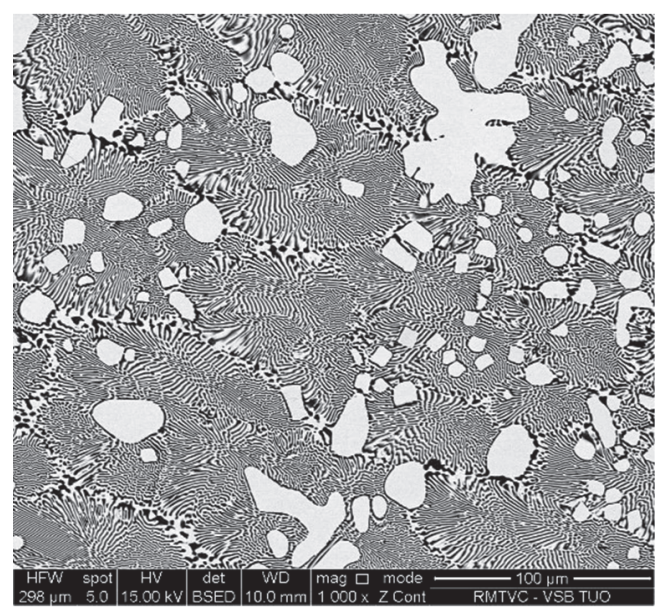

Figure 6 The microstructure of $\mathrm{Nb}-\mathrm{Al}-2$ master alloy (BSE)

Figure 7 show the BSE images of micro-structure of the master alloy Ta-Al. Structure of the prepared master alloy was dendritic with white dendrites of $\mathrm{TaAl}_{3}$ phase and the solid solution $\mathrm{Ta}$ in $\mathrm{Al}$ in the interdendritic areas. Average contents of elements in individual phases calculated from the measured chemical composition according to EDS were $24.9 \pm 0.2$ Ta for the white dendrites and $0.3 \pm 0.1$ at $\%$ Ta for the interdendritic areas. Occurrence of the mentioned phases was confirmed also by the $\mathrm{X}$-ray diffraction pattern (not presented in this article).
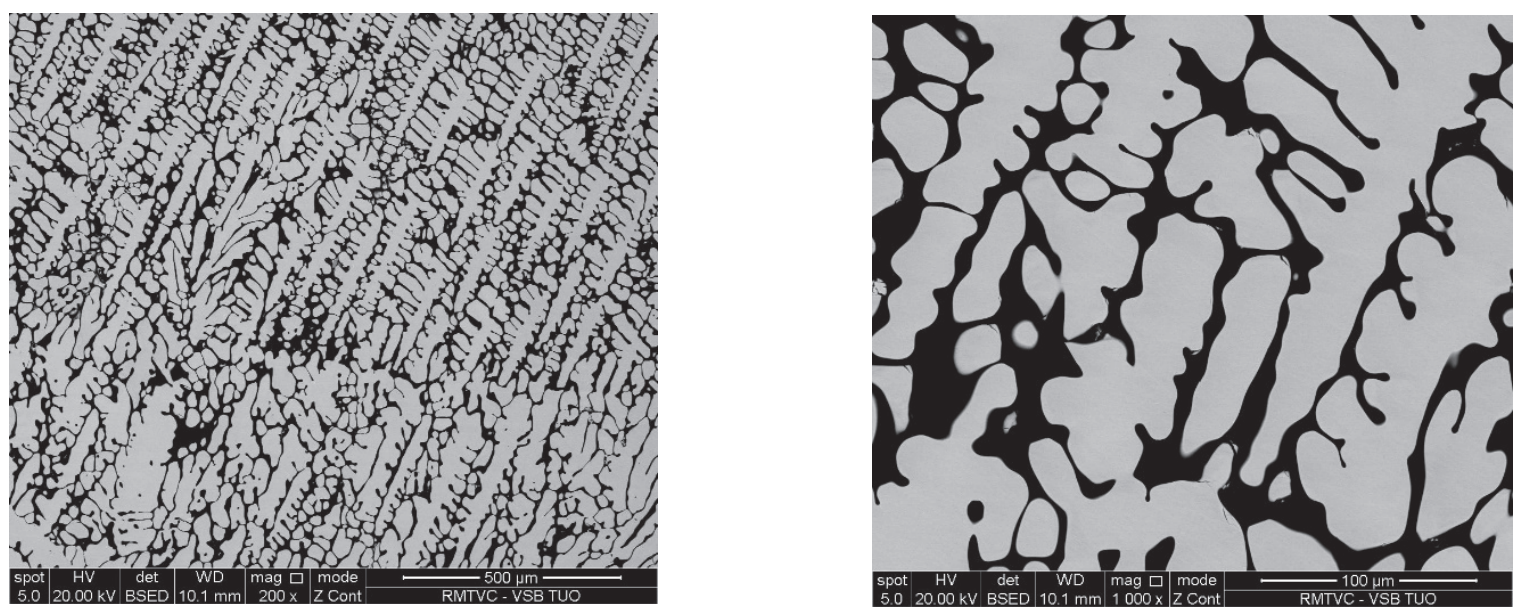

Figure 7 The microstructure of Ta-Al master alloy (BSE)

Typical microstructure of the W-Al master alloys ingots are shown in Figures 8, 9. As can be seen in these figures, the structure did not contain any undissolved $\mathrm{W}$ particles and usually consisted of needle-like WAl 4 particles (mS30), which chemical composition measured by EDS were between $19-25$ at $\% \mathrm{~W}$ and which are 
shown in the attached figures as light phase and Al matrix (W content up to 0.1 at\%), which are shown in figures by black colour. Occurrence of the mentioned phases was confirmed also by the X-ray diffraction pattern (not presented in this article).

Due to the anticipated use of the prepared ingots as master alloys suitable for preparing intermetallic alloys based on $\mathrm{y}$-TiAl, selected samples were subjected to differential thermal analysis (DTA) in order to determine the melting point. For the measurement were selected samples Nb-Al-2, Ta-Al and W-Al-2. Table 3 shows the individual melting points of the samples. These values thus confirm the appropriateness of the both master alloys for preparation intermetallic alloys based on $\mathrm{y}$-TiAl, because these temperatures are lower than melting temperature of pure $\mathrm{Ti}\left(1668{ }^{\circ} \mathrm{C}\right)$, which ensures easy melting of the master alloys with $\mathrm{Ti}$ and $\mathrm{Al}$ without requiring higher performance and melting times.

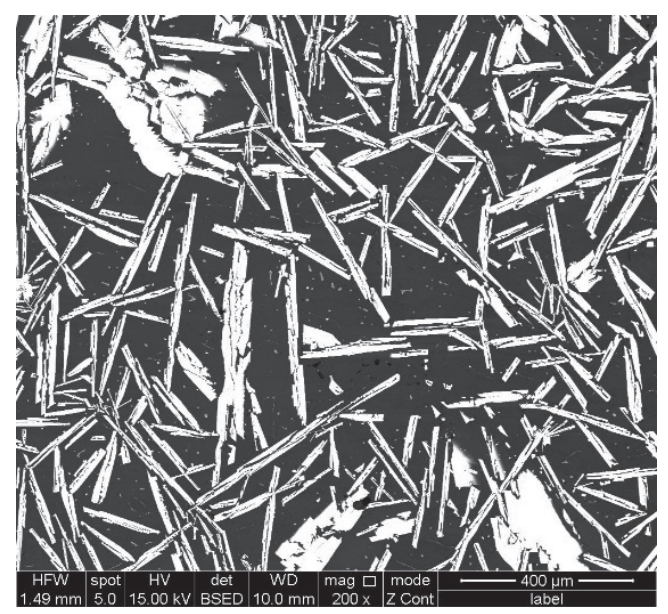

Figure 8 The microstructure of W-Al-2 master alloy (BSE)

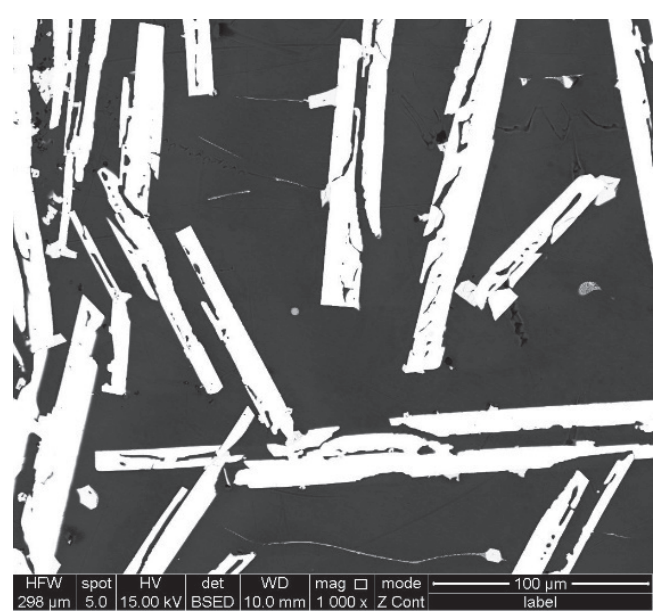

Figure 9 The microstructure of W-Al-1 master alloy (BSE)

Table 3 Detected liquidus temperatures by DTA

\begin{tabular}{cc} 
Alloy & Liquidus temperature $\left({ }^{\circ} \mathrm{C}\right)$ \\
\hline Nb-Al-2 & 1637 \\
Ta-Al & 1540 \\
W-Al-2 & 1350 \\
\hline
\end{tabular}

\section{CONCLUSION}

40Nb-60Al and 20Ta-80Al master alloys were prepared by PAM without any major problems. However, during the melting process, significant evaporation of Al was occurred and Al content in the alloys was reduced. 15W85AI master alloys after PAM contained non-melted parts of W. However, combination of PAM and VIM allows the preparation of W-Al master alloys without non-melted parts. Oxygen content of all prepared master alloys was less than $100 \mathrm{wt} \mathrm{ppm}$. The microstructure of master alloys contained no high melting phases, which would limit their use for the subsequent preparation of TiAl alloys. The liquidus temperature of all prepared master alloys was less than $1650^{\circ} \mathrm{C}$.

\section{ACKNOWLEDGEMENTS}

This paper was created within the projects of student grant competition SP2019 / 128 "Preparation and Optimization of Alloys Properties for Automotive, Electrical and Biomedical Applications and 


\section{Possibilities of their Recycling" and SP2019 / 43 "Specific Research in Metallurgical, Material and Process Engineering".}

\section{REFERENCES}

[1] WANG, Z., SUN, Y., ZHOU, Y., YANG, Z. and JIANG, F. Microstructure, precipitation and mechanical properties of a titanium-tungsten alloyed hot rolled high strength steel. Materials Science and Engineering: A. 2018. vol. 718, pp. 56-63. https://doi.org/10.1016/..msea.2018.01.105.

[2] ZHOU, T., FENG, W., ZHAO, H., MENG, Y., ZHANG, H., DING, H. and WANG, Z. H. Coupling effects of tungsten and molybdenum on microstructure and stress-rupture properties of a nickel-base cast superalloy. Progress in Natural Science: Materials International. 2018. vol. 28, No. 1, pp. 45-53.

https://doi.org/10.1016/j.pnsc.2017.12.003.

[3] SKOTNICOVA, K., KIRILLOVA, V.M., DRAPALA, J. and BURCHANOV, G.S. Structural changes of single crystals of low-alloyed tungsten alloys at thermal cycling. International Journal of Refractory Metals and Hard Materials. 2012. vol. 32, pp. 61-65. https://doi.org/10.1016/j.jirmhm.2012.02.001.

[4] BOCCHINI, P.J., SUDBRACK, K., SAUZA, D.J., NOEBE, R.D., SEIDMAN, D.N. and DUNAND, D.C. Effect of tungsten concentration on microstructures of Co-10Ni-6Al-(0,2,4,6)W-6Ti (at $\%)$ cobalt-based superalloys. Materials Science and Engineering: A. 2017. vol 700, pp. 481-486. https://doi.org/10.1016/j.msea.2017.06.018.

[5] TANG, L-Z., ZHANG, Z-G., LI, S-S. and GONG, S-K. Mechanical behaviors of NiAl-Cr(Mo)-based near eutectic alloy with Ti, Hf, Nb and W additions. Transactions of Nonferrous Metals Society of China. 2010. vol. 20, no. 2, pp. 212-216. https://doi.org/10.1016/S1003-6326(09)60123-0.

[6] SKOTNICOVA, K., KIRILLOVA V. M., DRAPALA, J., BURCHANOV, G.S., KUZMISHEV, V.A., SDOBYREV, V.V., DEMENTYEV, V.A. and ABRAMOV, N.N. Preparation and Investigation of Structural Parameters of Single Crystals of Low-Alloyed Alloys on the Base of Tungsten and Molybdenum. Advanced Engineering Materials. 2013. vol. 15, No. 10, pp. 927-934. https://doi.org/10.1002/adem.201300003.

[7] KASTENHUBER, M., RASHKOVA, B., CLEMENS, H. and MAYER, S. Enhancement of creep properties and microstructural stability of intermetallic $\beta$-solidifying $\mathrm{Y}$-TiAl based alloys. Intermetallics. 2015. vol. 63 pp.19-26. http://dx.doi.org/10.1016/j.intermet.2015.03.017.

[8] MIZUHARA, Y., HASHIMOTO, K. and MASAHASHIC, N. Microstructure and phase stability of TiAI-W ternary alloy. Intermetallics. 2003. vol. 11, pp. 807-816. http://dx.doi.org/10.1016/S0966-9795(03)00080-3.

[9] MORRIS, M.A. Dislocation mobility, ductility and anomalous strengthening of two-phase TiAl alloys: effects of oxygen and composition. Intermetallics. 1996. vol. 4, pp. 417-426. http://dx.doi.org/0966.9795(95)00060-7.

[10] GOMEZ, F., BARBOSA, J. and RIBEIRO, C.S. Aluminium evaporation during ceramic crucible induction melting of titanium aluminides. Materials Science Forum. 2013. vol.730-732, PP. 697-702.

https://doi.org/10.4028/www.scientific.net/MSF.730-732.697.

[11] YANGING, S., JINGJIE, G., JUN, J., GUIZHONG, L. and YUAN, L. Composition control of a TiAl melt during the induction skull melting (ISM) process. Journal of Alloys and Compounds. 2002. vol. 334, pp. 261-266.

https://doi.org/10.1016/S0925-8388(01)01766-2. 